\section{SAT0095 A PERCEIVED BIOLOGICAL CAUSE OF RHEUMATOID ARTHRITISONSET IS ASSOCIATED WITH LOWER LEVELS OF DEPRESSED AND ANXIOUS MOOD OVER ONE YEAR COMPARED TO PATIENTS WHO ATTRIBUTED ONSET TO OTHER CAUSES}

J. Gwinnutt ${ }^{1}$, S. Verstappen ${ }^{1,2}$, K. Hyrich ${ }^{1,2}$, M. Lunt ${ }^{1}$, A. Barton ${ }^{2,3}$,

L. Cordingley ${ }^{1}$ on behalf of RAMS coinvestigators. ${ }^{1}$ Arthritis Research UK Centre for Epidemiology, The University of Manchester, ${ }^{2} \mathrm{NIHR}$ Manchester Biomedical Research Centre, Manchester University Hospitals NHS Foundation Trust, ${ }^{3}$ Arthritis Research UK Centre for Genetics and Genomics, The University of Manchester, Manchester, UK

Background: Patients with rheumatoid arthritis $(\mathrm{RA})$ attribute onset of their condition to a range of causes including biological, psychological, work-related causes or stressful life events. Causal attributions are associated with a range of shortand long-term outcomes.

Objectives: To compare the 1 year outcomes of early RA patients who attribute a biological cause of onset of RA with patients who perceive non-biological causal attributions.

Methods: The Rheumatoid Arthritis Medication Study (RAMS) is a prospective cohort of patients with RA starting methotrexate for the first time in the United Kingdom. Demographic and clinical data (pain and fatigue visual analogue scales [VAS-pain/VAS-fatigue], disease activity [DAS28], the Hospital Anxiety and Depression Scale [HADS-A, HADS-D] and the Health Assessment Questionnaire [HAQ]) were collected at baseline and 1 year later. At baseline, patients completed the Brief Illness Perception Questionnaire (Brief IPQ), which assesses key beliefs about the impact, controllability, and chronicity of RA. The final item of the Brief IPQ asks patients to report the most important factor they believe caused their disease. These causal attributions were coded as either biological (e.g. age, genetics) or other causes (e.g. work related, stressful life event). Brief IPQ item response scores were compared between these groups using linear regression, adjusted for age and gender. HAQ, DAS28, VAS-pain, VAS-fatigue, HAD-A and HADS-D over follow-up were compared between the two groups using random effects models.

Results: Of 1171 patients, $483(41.2 \%)$ reported a biological cause to be the most important factor in causing their arthritis and 688 (58.8\%) reported a non-biological cause. Patients who believed in biological causes were younger (median 58 vs. 61 years; $p=0.003)$ and more likely to be women $(72.1 \%$ vs. $59.2 \%$; $\mathrm{p}<0.001)$. Other baseline characteristics were similar (Table). Patients who perceived biological causes reported significantly lower concerns about their illness (median: 8 vs. 9; $\mathrm{p}=0.004$ ) and significantly lower emotional impact (median: 5 vs. $6 ; p<0.001)$. Over follow-up, patients who attributed biological causes reported lower depression and anxiety HADS scores than those holding non-biological attributions (mean difference [95\% CI]: HADS- $D=-0.76$ [-1.19, -0.33]; HADS$A=-0.94[-1.41,-0.47])$. Other outcomes over follow-up were similar.

Abstract SAT0095 - Table 1. Baseline and one year characteristics, stratified by perceived cause of patients' illness

\begin{tabular}{|c|c|c|c|c|c|}
\hline \multirow[b]{2}{*}{ Characteristic } & \multicolumn{2}{|c|}{ Biological cause } & \multicolumn{3}{|c|}{ Other cause } \\
\hline & $\mathrm{N}$ & median(IQR) & $\mathrm{N}$ & median(IQR) & $p^{t}$ \\
\hline Age, years & 483 & $58(48,68)$ & 688 & $61(52,69)$ & 0.003 \\
\hline Female & $348(72.1)$ & & $407(59.2)$ & & $<0.001$ \\
\hline $\begin{array}{l}\text { Disease duration at } \\
\text { baseline, months }\end{array}$ & 483 & $7(4,11)$ & 688 & $6(3,11)$ & 0.094 \\
\hline \multicolumn{6}{|l|}{ Swollen joint count } \\
\hline Baseline & 469 & $4(2,9)$ & 650 & $4(2,9)$ & 0.822 \\
\hline One year & 301 & $1(0,3)$ & 409 & $1(0,3)$ & 0.527 \\
\hline \multicolumn{6}{|l|}{ Tender joint count } \\
\hline Baseline & 470 & $5(2,11)$ & 651 & $5(2,11)$ & 0.959 \\
\hline One year & 301 & $2(0,5)$ & 408 & $2(0,6)$ & 0.7823 \\
\hline \multicolumn{6}{|l|}{ DAS28 } \\
\hline Baseline & 457 & $4.2(3.3,5.1)$ & 630 & $4.2(3.3,5.2)$ & 0.690 \\
\hline One year & 271 & $3.0(2.3,4.0)$ & 386 & $2.8(2.1,4.0)$ & 0.283 \\
\hline \multicolumn{6}{|l|}{ HAQ Score } \\
\hline Baseline & 481 & $1.00(0.38,1.50)$ & 685 & $1.00(0.50,1.63)$ & 0.602 \\
\hline One year & 287 & $0.75(0.13,1.25)$ & 376 & $0.63(0.13,1.25)$ & 0.996 \\
\hline \multicolumn{6}{|l|}{ HADS-D } \\
\hline Baseline & 479 & $4(2,8)$ & 682 & $6(2,9)$ & 0.001 \\
\hline One year & 285 & $3(1,7)$ & 374 & $4(1,7)$ & 0.071 \\
\hline \multicolumn{6}{|l|}{ HADS-A } \\
\hline Baseline & 479 & $5(3,5)$ & 682 & $6(3,10)$ & 0.010 \\
\hline One year & 285 & $4(2,8)$ & 372 & $5(2,8)$ & 0.130 \\
\hline
\end{tabular}

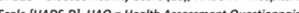

Conclusions: Different causal attributions of RA are associated with different outcomes and may suggest that education about RA causality could improve patientcentred outcomes; however, that would require further evaluation.

Disclosure of Interest: None declared

DOI: 10.1136/annrheumdis-2018-eular.5234

\section{SAT0096 WINDOW OR NO WINDOW: EARLIER IS BETTER WHEN TREATING RHEUMATOID ARTHRITIS}

J.A. van der Pol ${ }^{1}$, S.A. Bergstra ${ }^{1}$, N. Riyazi ${ }^{2}$, Y.P. Goekoop-Ruiterman ${ }^{2}$,

A. Chopra ${ }^{3}$, P. Kerstens ${ }^{4}$, W.F. Lems ${ }^{5}$, R. Tsonaka ${ }^{6}$, T.W. Huizinga ${ }^{1}$, C.F. Allaart ${ }^{1}$.

${ }^{1}$ Rheumatology, LUMC, Leiden; ${ }^{2}$ HAGA Hospital, The Hague, Netherlands; ${ }^{3} \mathrm{CRD}$,

Pune, India; ${ }^{4}$ Amsterdam Rheumatology and Immunology Center, Reade;

${ }^{5}$ Rheumatology, VUMC, Amsterdam; ${ }^{6}$ Medical Statistics and Bioinformatics,

LUMC, Leiden, Netherlands

Background: Previous reports on a window of opportunity in rheumatoid arthritis (RA) may be related to the use of slow acting c(onventional) s(ynthetic) DMARDs. We hypothesised that onset of action of therapy might influence whether there is a window of opportunity or whether 'earlier is just better'.

Objectives: To investigate the association between symptom duration at treatment onset and the achievement of sustained drug free remission (sDFR) in early RA patients initiating therapy including fast acting prednisone or infliximab, compared to patients initiating csDMARD monotherapy.

Methods: We analysed the shape (hyperbolic or linear) of the association between symptom duration and achievement of SDFR (DAS $<1.6$ and no DMARDs for $>1$ year) for patients initiating combination therapy in 3 cohorts: BeSt, IMPROVED study and METEOR. All patients had arthritis symptoms $<2$ years. In the BeSt study, early RA patients (1987 criteria) were randomised to 4 targeted treatment strategies: arm 1 and 2 started with csDMARD monotherapy, arm 3 with csDMARDs and tapered high dose prednisone and arm 4 with csDMARD and infliximab. Subsequent treatment adjustments aimed at DAS $\leq 2.4$. In the IMPROVED study early RA patients (2010 criteria) were treated with csDMARD and tapered high dose prednisone. Subsequent treatment adjustments aimed at DFR. METEOR is an international observational cohort including daily practice data from patients with a diagnosis and treatment of RA according to the rheumatologist. We selected patients who started on csDMARD monotherapy or a combination of csDMARD with prednisone or anti-TNF and at least 1.5 year follow-up.

Missing DAS were imputed using last observation carried forward. We performed Cox regression analyses with as outcome sDFR and as predictor symptom duration and compared the likelihood ratio tests of a linear model and a model with inclusion of natural cubic spline functions (resulting in a hyperbola), to investigate which model was a better fit for the data.

Results: In BeSt ( $n=469)$, IMPROVED ( $n=421)$ and METEOR ( $n=1653)$ 54, 110 and 10 patients who started with csDMARD and prednisone or anti-TNF combination therapy, and 53 in BeSt and 15 in METEOR who started with csDMARD monotherapy (no monotherapy in IMPROVED) achieved SDFR. A hyperbolic model did not show a better fit for the data than a linear model (for combination therapy in BeSt $p=0.743$, IMPROVED $p=0.337$, METEOR $p=0.608$, for csDMARD monotherapy in BeSt $p=0.609$, in METEOR $p=0.758$ ). Figure 1 shows the linear association between symptom duration and sDFR per study. These results indicate that the earlier treatment is started, the higher the likelihood of achieving sDFR. However, the data do not suggest that a hyperbolic relationship between treatment onset and outcome sDFR fit the data better.
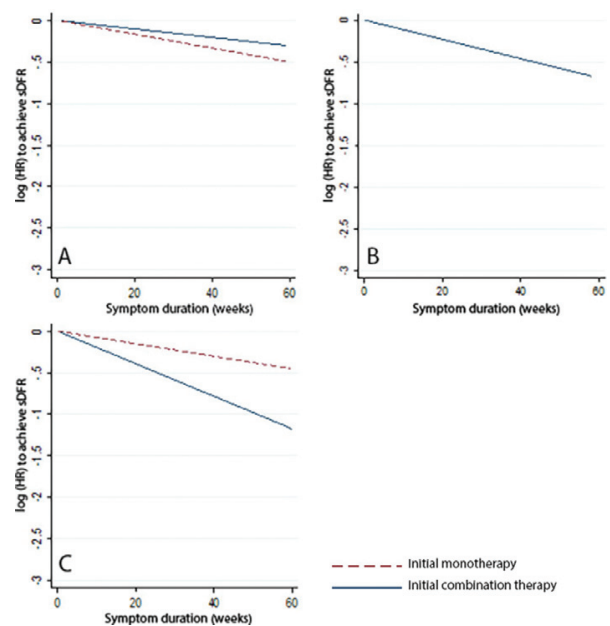

Conclusions: Our data suggest that there is no evidence for a window of opportunity in early RA in 3 cohorts. This was not related to use of fast acting combination therapy including prednisone or anti-TNF instead of slow acting csDMARD monotherapy nor was it dependent on strict treatment to target in a clinical trial. It remains that earlier treatment initiation is better when aiming to achieve sDFR. 
Disclosure of Interest: J. van der Pol: None declared, S. A. Bergstra: None declared, N. Riyazi: None declared, Y. Goekoop-Ruiterman: None declared, A. Chopra: None declared, P. Kerstens: None declared, W. Lems: None declared, R. Tsonaka: None declared, T. Huizinga Consultant for: UCB, BMS, Pfizer, Roche, Sanofi-Aventis and Boeringher from outside the submitted work., C. Allaart Grant/ research support from: The IMPROVED study was designed by the investigators and financially supported during the first year of follow-up by AbbVie. The BeSt study was supported by the Dutch College of Health Insurances, with an additional grant from Schering-Plough BV and Centocor Inc.

DOI: 10.1136/annrheumdis-2018-eular.1743

\section{SAT0097 RISK OF PREVENTABLE HOSPITALISATION BEFORE AND AFTER DIAGNOSIS AMONG RHEUMATOID ARTHRITIS PATIENTS COMPARED TO CONTROLS}

C.-F. Kuo ${ }^{1,2}$, P.B. Burns ${ }^{3}$, J.-S. Chen ${ }^{2}$, L. Wang ${ }^{4}$, K.C. Chung ${ }^{3} .{ }^{1}$ Academic Rheumatology, University Of Nottingham, Nottingham, UK; ${ }^{2}$ Division of Rheumatology, allergy and Immunology, Chang Gung Memorial Hospital, Taoyuan, Taiwan, Province of China; ${ }^{3}$ Section of Plastic Surgery; ${ }^{4}$ Department of Biostatistics, School of Public Health, University of Michigan, Ann Arbor, USA

Background: Rheumatoid arthritis (RA) generally requires intensive medical intervention, which along with the progression of the disease itself, may lead to the occurrence of comorbidities and hospitalisation that can be prevented with a quality primary care. We assessed the risk of preventable hospitalizations in RA patients, for whom preventable hospitalizations have not been well studied. We compare the incidence rate of preventable hospitalizations in newly-diagnosed RA patients and non-RA patients using data from the Taiwan National Health Insurance (NHI) Database.

Objectives: To investigate the risk of preventable hospitalisation before and after diagnosis between RA and non RA patients.

Methods: 11852 incident RA patients and 59260 age-, sex-, and index yearmatched controls were identified from the Taiwan National Health Insurance Database. Index date was defined as the initial diagnosis date for RA patients and this date was assigned to their matched controls. The incidence and incidence rate ratios (IRRs) of preventable hospitalisation between RA patients and controls were estimated using conditional Poisson regression adjusted for age, sex, Elixhauser Comorbidity Index, number of outpatient visits and hospitalizations 1 year prior to index date, residence urbanisation, income levels, occupation and the number of physicians practicing near the patients' residence.

Results: The overall incidence of preventable hospitalisation in RA patients and controls was 1.71 vs 0.95 events per 1000 person-months, corresponding to adjusted incidence rate ratio (IRR) of $1.43(95 \% \mathrm{Cl}, 1.35-1.51)$. The crude IRR for preventable hospitalisation was 1.84 (1.61-2.11) one year prior to RA diagnosis. Adjusted IRRs $(95 \% \mathrm{Cl})$ for preventable hospitalisation categories were 1.43 (1.22-1.67) for chronic obstructive pulmonary disease, $1.28(1.02-1.62)$ for asthma, $1.76(1.62-1.91)$ for bacterial pneumonia, $1.47(1.35-1.61)$ for urinary tract infection.

Conclusions: This population-based study indicates that RA is independently associated with a higher risk of preventable hospitalisation, and the risk was already greater prior to formal diagnosis of RA. These results signal gaps in the care and management of RA patients in this population.

\section{REFERENCE:}

[1] Billings J, Anderson GM, Newman LS. Recent findings on preventable hospitalizations. Health Aff (Millwood) 1996;15(3):239-249.

Disclosure of Interest: None declared DOI: 10.1136/annrheumdis-2018-eular.6663

\section{SAT0098 \\ PATIENT AND DISEASE CHARACTERISTICS THAT PREDICT SWITCHING FROM A TNF INHIBITOR TO ANOTHER BIOLOGIC OR TARGETED SYNTHETIC DMARD IN PATIENTS WITH RA IN CLINICAL PRACTICE}

L.R. Harrold ${ }^{1}$, H.J. Litman ${ }^{2}$, S.E. Connolly ${ }^{3}$, E. Alemao ${ }^{3}$, S. Kelly ${ }^{3}$, S. Rebello ${ }^{2}$, T. Blachley ${ }^{2}$, J.M. Kremer ${ }^{4}$. 'University of Massachusetts Medical School, Worcester, ${ }^{2}$ Corrona LLC, Waltham; ${ }^{3}$ Bristol-Myers Squibb, Princeton; ${ }^{4}$ Albany Medical College and The Center for Rheumatology, Albany, USA

Background: Specific patient demographics or disease characteristics may be associated with switching from one therapy to another for patients with RA. Identifying these predictive factors may help inform prospective treatment decisions. Objectives: To examine factors predicting switching among patients with RA from a TNF inhibitor (TNFi) to a subsequent biologic (b)DMARD (TNFi or nonTNFi [abatacept, tocilizumab, rituximab]) or the targeted synthetic (ts)DMARD tofacitinib.
Methods: This analysis included patients aged $\geq 18$ years, who were enrolled in a large sequential RA registry established in October 2001 and who initiated a TNFi on/after 1 January 2005 and had $\geq 24$ months' follow-up. Switch was defined as discontinuation of a TNFi and initiation of another bDMARD or tofacitinib within 6 months. Of TNFi initiations, $67 \%$ were randomly selected as a prediction datase and used to develop the final model; $33 \%$ were considered in the validation dataset. Logistic regression modelling was used to predict switching status; baseline demographics (age, sex, race), patient attributes (smoking status, BMI, work status) and clinical characteristics (RF and anti-cyclic citrullinated protein status, erosive disease, history of co-morbidities, prior and current treatment, disease activity, patient-reported pain, fatigue, morning stiffness) were considered. Goodness-of-fit statistics were used to assess model fit and receiver operating charac teristic curves (area under the curve [AUC]) to validate the model.

Results: Among 6909 eligible TNFi initiations, there were 1343 switchers (predic tion dataset: 4623 TNFi initiations, including 898 switchers). Compared with nonswitchers, switchers were younger, had a shorter duration of RA and higher baseline mean CDAI score. Fewer switchers were positive for erosive disease or on combination therapy with MTX, but more were on monotherapy or combination therapy with a non-MTX DMARD. After investigation of several models, the bestfit model (Table) to predict switching from a TNFi yielded an AUC $=0.705$ (sensitivity $=81 \%$; false positive rate $=49 \%$ )

Table 1. Predictive Model for TNFi Switching in Patients with RA

\begin{tabular}{|c|c|c|c|}
\hline Covariate & Value & $\begin{array}{l}\text { Odds ratio } \\
(95 \% \mathrm{Cl})\end{array}$ & $p$ value \\
\hline Age (10 year effect) & & $0.85(0.79-0.92)$ & $<0.0001$ \\
\hline \multirow[t]{4}{*}{ Duration of RA, years } & $0-2$ & Reference: & \\
\hline & $3-5$ & $0.85(0.67-1.07)$ & 0.17 \\
\hline & $6-10$ & $0.65(0.51-0.85)$ & 0.001 \\
\hline & $>10$ & $0.52(0.41-0.66)$ & $<0.0001$ \\
\hline History of diabetes & & $1.26(0.94-1.68)$ & 0.12 \\
\hline History of malignancy & & $0.66(0.47-0.94)$ & 0.02 \\
\hline History of serious infection & & $1.16(0.82-1.64)$ & 0.41 \\
\hline $\begin{array}{l}\text { Prior number of conventional } \\
\text { DMARDs }\end{array}$ & & $1.17(1.08-1.27)$ & 0.0002 \\
\hline \multirow[t]{3}{*}{ Number of prior non-TNFi } & 0 & Reference: & \\
\hline & 1 & $1.17(0.88-1.55)$ & 0.29 \\
\hline & $\geq 2$ & $1.36(0.90-2.05)$ & 0.15 \\
\hline \multirow[t]{4}{*}{ CDAI score } & Remission (0-2.8) & Reference: & \\
\hline & Low $(>2.8-10)$ & $1.72(1.11-2.66)$ & 0.01 \\
\hline & Moderate (>10-22) & $2.75(1.82-4.16)$ & $<0.0001$ \\
\hline & High $(>22)$ & $2.75(1.82-4.14)$ & $<0.0001$ \\
\hline Year of initiation & & $1.33(1.28-1.37)$ & $<0.0001$ \\
\hline
\end{tabular}

Conclusions: The model identified in this analysis revealed that factors including age, duration of RA, CDAl, history of co-morbid conditions, prior treatment and year of TNFi initiation predicted switching from a TNFi to another bDMARD or tsDMARD.

Disclosure of Interest: L. Harrold Shareholder of: Corrona, LLC, Grant/research support from: Pfizer, Consultant for: Roche, Bristol-Myers Squibb, Employee of: Corrona, LLC, University of Massachusetts Medical School, H. Litman Employee of: Corrona, LLC, S. Connolly Shareholder of: Bristol-Myers Squibb, Employee of: Bristol-Myers Squibb, E. Alemao Shareholder of: Bristol-Myers Squibb, Employee of: Bristol-Myers Squibb, S. Kelly Shareholder of: Bristol-Myers Squibb, Employee of: Bristol-Myers Squibb, S. Rebello Employee of: Corrona, LLC, T. Blachley: None declared, J. Kremer Shareholder of: Corrona, LLC, Grant/research suppor from: AbbVie, Bristol-Myers Squibb, Genentech, Lilly, Novartis, Pfizer, Employee of: Corrona, LLC, Speakers bureau: Genentech (non-branded talks only) DOI: 10.1136/annrheumdis-2018-eular.1581

\section{SAT0099 SARCOPENIA IS ASSOCIATED WITH JOINT DAMAGE IN RHEUMATOID ARTHRITIS: A CROSS-SECTIONAL STUDY}

J.-Z. Lin ${ }^{1}$, Y.-Y. Wang ${ }^{2}$, P.-J. Liu², Y.-Q. Mo ${ }^{1}$, Q.-H. Li ${ }^{1}$, W.-M. Cheng ${ }^{3}$, X.-L. He ${ }^{3}$, L. Dai ${ }^{1} .{ }^{1}$ Rheumatology, Sun Yat-sen Memorial Hospital, Sun Yat-sen University; ${ }^{2}$ Zhongshan School of Medicine, Sun Yat-sen University, Guangzhou; ${ }^{3}$ Shanghai Healthare Co. Ltd, Zhangjiang Innopark, Shanghai, China

Background: The association of metabolic status with disease characteristics of rheumatoid arthritis (RA) remain controversial. Body composition (BC) instead of body mass index (BMI) has been more and more recommended to assess metabolic status.

Objectives: To investigate the characteristics of BC in RA patients and their association with RA disease characteristics.

Methods: BC was assessed in RA patients and control subjects by bioelectric impedance analysis. Overfat was defined by body fat percentage (BF\%) as $\geq 25 \%$ for men and $\geq 35 \%$ for women. Sarcopenia was defined by skeletal muscle mass 